\title{
Effect of Fast-Food-Based Hyper-Alimentation on Liver Enzymes In Healthy Nigerian Youths
}

\author{
Oyedepo T.A ${ }^{1} *$, Sodamade A. ${ }^{2}$ and Odefunso A.E. ${ }^{3}$ \\ ${ }^{I}$ Biochemistry Programme, Department Of Basic Sciences, Adeleke University, P.M.B. 250, Ede \\ ${ }^{2}$ Department Of Chemistry, Emmanuel Alayande College Of Education, P.M.B.1010, Oyo \\ ${ }^{3}$ Department Of Pure And Applied Chemistry, Ladoke Akintola University Of Technology, Ogbomoso
}

\begin{abstract}
Fast-food eating is a dietary pattern that used to be foreign but has gradually become a part of the lifestyle of people in Nigeria especially those in urban areas. It is great tasting, affordable, and can be found just about everywhere. The temptations of these favorite fast foods and cafe treats often pose challenges for those who are trying to stick to limited-calorie diets. Hyper-alimentation refers to a state where quantities of food consumed are greater than appropriate. This study was designed to evaluate the effect of fast-food-based hyper-alimentation on liver enzymes. Prospective interventional study with parallel control group was used for the study. Sixteen healthy youths (10 men and 6 women) with a mean (SD) age of 24 (4.3) years and a matched control group were used for the study. Subjects in the intervention group were made to aim for a body weight increase of 5-15\% by eating at least two fast-food-based meals a day with the goal to double the regular caloric intake in combination with adoption of a sedentary lifestyle for 4 weeks. Weekly changes of serum aminotransferases were measured by UV spectroscopy at baseline and after the intervention. The weight of subjects in the intervention group increased from $55.8(8.7) \mathrm{kg}$ to $64.2(8.9) \mathrm{kg}(p<0.001)$. Serum Alanine transferase (ALT) increased from 20.4 (9.5) U/l at the beginning of the study to a maximum level of 58.5 (12) U/l (normal range 7 - 56 U/l). Aspartate Aminotransferase (AST) increased from 28.7 (14) U/l to 41.2 (20) U/l (normal range 5 - $40 \mathrm{U} /$ ) while Alkaline Phosphatase (ALP) also increased from 35.6 (13) U/l to 66.5 (14)U/l [normal range: 25 -100U/l]. It was however observed that serum aminotransferases levels, ALP and body weight were not significantly altered in the control subjects. The results of this study is therefore an indication that fast-food hyper-alimentation can trigger the elevation of liver marker enzymes which is an indication for the onset of fatty liver diseases.
\end{abstract}

Keywords: Aminotransferases; Diet-intervention; Fast-foods; Hyper-alimentation; Liver Enzymes.

\section{Introduction}

Fast food eating, a dietary pattern that used to be uniquely foreign has gradually become part of the lifestyle of people in Nigeria, especially those in urban centre [1,2]. In many cities in Nigeria, there are numerous fast food restaurants where most of the foods sold are usually snacks, burgers, fries, chicken, cola drinks, ice cream, fruit drinks and other foods that are high in fat, sodium and sugar [3]. The growth of this business can be noted in the fact that the number of fast food eating establishments scattered all over major streets of big cities increased in the past few years with different exotic and enticing names. Before now, eating at home was the culture of Nigerians and people who eat out are usually travelers. As a matter of fact most of such outlets are located near garages for easy access. However, the situation is now very different as Nigerians have also adopted the idea of eating out on a regular basis which may be due to but not limited to peoples' jobs. The high rate of increase is evident in the growing population of such food vendors also [4]. Most of these fast foods are high in sugar, sodium, and fat [5].

The history of fast food sales in Nigeria started with companies like U.A.C, Kingsway, Leventis and UTC, who were foreign investors. They made food for those who were rich and could not wait till they get home to eat food. At that time eating out was considered for the wealthy alone as these fast foods were more expensive than the regular meal prepared at home. This business continued to grow until indigenous people started selling local foods too. The establishment of fast food sales outlets by Mr Biggs in 1986 promoted the modern fast food business in Nigeria [4]. Today fast food business is everywhere in Nigeria and it is growing. There are now several outlets for indigenous and foreign foods in every nook and corner of Nigeria. This increase in accessibility has made it the first option for most people.

The dangers associated with the consumption of these junk foods available everywhere is more of hygiene and lack of control over the basic constituents of the food. Most of these fast foods are made with lots of sweeteners necessarily because the owners want to beat other competitors in taste. However, this business idea is affecting consumers in that they rarely get the essential nutrients expected of a healthy diet. Not only this, such people gain weight but are highly deficient $[6,7]$. Another danger associated with junk food consumption is that, in most cases, people consume more than is needed. This leads to obesity problems and other health 
issues. The prevalence of overweight and obesity has increased in many parts of the world as well as in Sweden during the past few decades [8]. Lifestyle factors such as consumption of high energy dense food, but also lack of physical activity, contribute to the development of overweight and obesity [9].

Hyper-alimentation is defined as overfeeding or the ingestion or administration of an amount of nutrients that exceeds the demands of the appetite. It is most times medically referred to as parenteral nutrition [10]. Hyperalimentation has been associated with laboratory evidence of hepatic dysfunction and morphologic evidence of hepatic steatosis and cholestasis. A recent study which evaluated the effect of intravenous caloric support on hepatic lipid metabolism in rats and man showed that hyperalimentation is associated with increased hepatic lipid accumulation in rats and man as overeating SFAs promotes hepatic and visceral fat storage [11]. This conclusion was drawn after investigating liver's fat accumulation and body composition during overfeeding with saturated fatty acids (SFAs) or polyunsaturated fatty acids (PUFAs). With thirty-nine adults fed muffins with extra SFAs for seven weeks they markedly increased liver fat. Lecoulture et al [12] opined that short-term overfeeding with fructose or glucose decreases hepatic insulin sensitivity and increases hepatic fat content.

This study was undertaken to investigate the effects of 4 weeks of fast-food-based hyper-alimentation on levels of serum aminotransferases and on hepatic triglyceride content (HTGC) measured by spectroscopic methods. The purpose of the study was to investigate the potential link between changes of serum aminotransferases (i.e. ALT, ALP and AST) to the amount of hepatic fatty permeation in healthy non-obese subjects during a positive energy balance resulting in a weight gain of 5-15\%.

\subsection{The Intervention group}

\section{Materials and Methods}

Sixteen healthy youths (10 men and 6 women) with a mean (SD) age of 24 (4.3) years and a matched control group were used for the study. They were recruited by personal consent as volunteers for the intervention group of the study. All subjects were postgraduate students in Nigerian universities. All participants agreed to an increase in body weight of 5-15\% and to eat at least two fast-food-based meals a day, preferably at established fast-food restaurants. The cost for the food was successively refunded based on the food receipts. Physical activity was not to exceed 5000 steps per day. If a study subject reached a weight gain of $15 \%$ he or she has to terminate the study as soon as possible by re-performing the same study investigations as were done at baseline. The participants were free from current diseases as judged by medical check-up and history.

All subjects in the intervention group continually had contact with the principal investigator, by weekly meetings or by phone, during the study. The dietary advice was individually adjusted to result in an intake corresponding to doubling the present caloric requirement. The 16 subjects for both the control and intervention groups were not into alcohol consumption in any form.

The composition of the diet was determined based on reports from 3 days before the study and another two 3-day periods at the end of the first or third weeks. The exact food composition given by the corresponding fast-food restaurant was used as the source of information for caloric intake, but if such information was incomplete, food composition charts were alternatively used. The total caloric intake was also determined for the whole study period, and was based on receipts and oral interviews.

\subsection{Control group}

An age- and gender-matched control group was also recruited mainly to allow discrimination of changes of liver enzymes induced by food intake from random fluctuations. The control group performed the laboratory investigations and anthropometric measurements at baseline and after 4 weeks, as well as measurement of basal metabolic rate.

\subsection{Biochemical Assays}

Blood for laboratory tests was drawn in the fasting state at baseline, i.e. before starting on the extra caloric intake, after 2 weeks on the fast-food-based diet and at the end of the study, i.e. at the end of fourth week. Blood was also drawn in the non-fasting state at the end of the first and the third study weeks, to monitor changes in serum liver enzyme levels.

Blood samples were obtained by means of a $5 \mathrm{ml}$ hypodermic syringe and needle. The blood samples were introduced into clean, dry bottles without anticoagulants for serum separation. The bottles and its contents were centrifuged at 3000 rpmat $4{ }^{\circ} \mathrm{C}$ for 10 minutes. Serum was collected into a clean, dry sample container. The serum was used for measurement of various biochemical markers i.e. L-aspartate aminotransferase (AST), Lalanine transferase (ALT) using the method of Reitman and Frankel [13]. Total serum bilirubin was measured in $\mathrm{mg} / \mathrm{dL}$ using the LX20, which uses a timed-endpoint Diazo method to measure the total concentration of bilirubin [14]. Alkaline phosphatase (ALP) activity was determined based on the reaction principle of Heins et al. [15]. 


\subsection{Determination of Basal Metabolic Rate}

Basal metabolic rate was measured using a ventilated hood technique [16] in the fasting state in the morning and the mean value of one measurement per minute during the last $6 \min$ of a $15 \min$ period was calculated. All the investigations were performed at baseline and during the last week of the study, except for the recording of basal metabolic rate, which was also measured in the fasting state after 2 weeks on the diet.

\subsection{Statistical Analysis}

Statistical designs were done with SPSS 14.0 software (SPSS Inc. Chicago, IL, USA). Linear correlations were calculated and comparisons within and between groups were done with the Student paired and unpaired twotailed t- test or as stated in the results section. Mean (SD) is presented unless otherwise stated. Statistical significance was considered at the 5\% level $(\mathrm{p} \leqslant 0.05)$.

\subsection{Research Ethics}

Written informed consent was obtained from all participating subjects.

\section{Results and Discussion}

The Anthropometric and laboratory data before and after the hyper-alimentation in the intervention group and before and after 4 weeks on regular diet and exercise habits in the control group is presented in TABLE 1 below.

It will be observed from the table that there was a significant increase in the weight, BMI, SAD, waist and hip circumference, ALT, AST, ALP and basal metabolic rate of the intervention group while insignificant change was observed for those parameters for the control group. This shows that fast-food hyper alimentation affects significantly consumers' weight, BMI, SAD, waist and hip circumference, ALT, AST, ALP and basal metabolic rate. This agrees with previous observations by Rosquivist et al [17] and Lecoulture et al [18]. The bilirubin levels in the study however decreased in the intervention group from $0.75(0.15)$ to $0.58(0.15)$.

The control group in this study demonstrated comparable anthropometric data as the intervention group but had statistically significantly higher albumin throughout the study. As shown in TABLE 1, there was no change in ALT levels in the control group and the baseline ALT was similar in the intervention and the control groups. The difference at the end of the study between the two intervention and the control groups was statistically significant $(\mathrm{p}=0.001)$.

TABLE 2 shows the food composition of hyper-alimentation in the intervention group before and during the study while TABLE 3 shows the number of subjects in the intervention group who displayed serum ALT above reference levels during the study and even at follow-up.

The results in TABLE 3 show that the serum ALT level was higher in almost all of them by the end of the fourth week and this consistently increased from week one till week four. After the study period, it will be observed that the serum level did not just automatically drop after the study period. A week after the study many of the subjects still had the serum ALT level at the point they were after a week of intervention.

Table 1: Anthropometric and Laboratory Data Before and After the Hyper-

\begin{tabular}{|c|c|c|c|c|c|c|c|}
\hline \multicolumn{8}{|c|}{ Alimentation } \\
\hline Variable & $\begin{array}{l}\text { Interv. grp } \\
\text { before } \\
\text { diet }\end{array}$ & $\begin{array}{l}\text { Interv. grp } \\
\text { after diet }\end{array}$ & $\begin{array}{l}\text { p Value for } \\
\text { baseline vs } \\
\text { after diet in } \\
\text { interv. } \\
\text { group }\end{array}$ & $\begin{array}{l}\text { Control } \\
\text { group at } \\
\text { baseline }\end{array}$ & $\begin{array}{l}\text { p Value for } \\
\text { baseline in } \\
\text { control } \\
\text { group vs } \\
\text { interv. group }\end{array}$ & $\begin{array}{l}\text { Control grp } \\
\text { after } 4 \text { weeks }\end{array}$ & $\begin{array}{l}\mathrm{p} \text { Value for } \\
\text { levels at } \\
\text { study end } \\
\text { in control } \\
\text { vs interv. } \\
\text { group }\end{array}$ \\
\hline Age (years) & $24(4.5)$ & & & $24(4.1)$ & 0.3 & & \\
\hline $\operatorname{Sex}(M / F)$ & $10 / 6$ & & & $10 / 6$ & & & \\
\hline Weight (kg) & $55.8(8.7)$ & $64.2(8.9)$ & $<0.001$ & $59.2(3.8)$ & 0.5 & $59.6(7.4)$ & 0.2 \\
\hline $\begin{array}{l}\text { Body mass index } \\
\left(\mathrm{kg} / \mathrm{m}^{2}\right)\end{array}$ & $21.9(1.9)$ & $23.9(2.2)$ & $<0.001$ & $22.2(2.1)$ & 0.7 & $22.2(2.2)$ & 0.02 \\
\hline $\begin{array}{l}\text { Sagittal } \\
\text { abdominal } \\
\text { diameter }(\mathrm{cm})\end{array}$ & $17.8(1.5)$ & $21.2(1.3)$ & $<0.001$ & $17.6(1.4)$ & 0.3 & $17.7(1.8)$ & $<0.0001$ \\
\hline $\begin{array}{l}\text { Waist } \\
\text { circumference } \\
(\mathrm{cm})\end{array}$ & $75.3(5.2)$ & $85.3(6.6)$ & $<0.001$ & $74.9(4.4)$ & 0.7 & $75.2(4.8)$ & 0.002 \\
\hline $\begin{array}{l}\text { Hip } \\
\text { circumference(c } \\
\mathrm{m})\end{array}$ & $87.6(5.4)$ & $89.8(7.5)$ & 0.03 & $87.9(1.2)$ & 0.3 & $88.8(5.2)$ & 0.8 \\
\hline ALT (U/l) & $20.4(9.5)$ & $58.5(12)$ & 0.01 & $21.5(4.2)$ & 0.7 & $22.3(5.5)$ & 0.001 \\
\hline AST (U/l) & $28.7(14)$ & $41.2(20)$ & 0.07 & $25.2(7.2)$ & 0.8 & $25.8(9.0)$ & 0.02 \\
\hline
\end{tabular}


Effect Of Fast-Food-Based Hyper-Alimentation On Liver Enzymes In Healthy Nigerian Youths

\begin{tabular}{|l|l|l|l|l|l|l|l|}
\hline ALP (U/l) & $35.6(13)$ & $66.5(14)$ & 0.1 & $54.7(15)$ & 0.6 & $53.6(18)$ & 0.2 \\
\hline $\begin{array}{l}\text { Hepatic } \\
\text { triglyceride } \\
\text { content (\%) }\end{array}$ & $1.3(2.1)$ & $3.0(3.2)$ & $0.003^{*}$ & ND & ND & & \\
\hline Bilirubin (mg/dl) & $\begin{array}{l}0.75 \\
(0.15)\end{array}$ & $\begin{array}{l}0.58 \\
(0.15)\end{array}$ & 0.01 & $0.78(0.26)$ & 0.1 & $0.77(0.19)$ & 0.008 \\
\hline Albumin (g/dl) & $4.5(0.25)$ & $4.2(0.21)$ & 0.2 & $4.6(0.15)$ & 0.01 & $4.5(0.25)$ & 0.002 \\
\hline $\begin{array}{l}\text { Basal metabolic } \\
\text { rate (kcal/24 h) }\end{array}$ & $\begin{array}{l}1567 \\
(223)\end{array}$ & $1923(327)$ & 0.001 & $1654(292)$ & 0.3 & $1756(188)$ & 0.3 \\
\hline
\end{tabular}

Figures are presented as means (SD); Interv. grp. = intervention group; BMI=body mass index; ALT= alanine aminotransferase; $A S T=$ aspartate aminotransferase; $A L P=$ alkaline phosphatase.

*Comparison made with the Wilcoxon signed rank test. Conversions: ALT, AST and ALP (U/l) $\times 0.017=\mu \mathrm{kat} / \mathrm{l}$, Bilirubin $(\mathrm{mg} / \mathrm{dl}) \times 17.1=\mu \mathrm{mol} / \mathrm{l}$, albumin $(\mathrm{g} / \mathrm{dl}) \times 10=\mathrm{g} / \mathrm{l}$.

Increase in the level of aminotransferases in either sex is strongly linked with features of the metabolic syndrome like abdominal adiposity, high plasma glucose levels and dyslipidaemia [19]. As a matter of fact, high serum levels of AST and ALT are connected with future risk of developing type II diabetes [20]. A good number of aminotransferase elevations in apparently healthy subjects have previously generally been attributed to non-alcoholic fatty liver disease (NAFLD) [21]. Liver biopsy studies of patients referred for aminotransferase elevations have often presented liver steatosis in histological finding (Leung, Williams, Fraley and Klish, 2009). It has been demonstrated recently that subjects with NAFLD and elevated aminotransferases have a significant risk of developing end-stage liver disease and a minor chance of survival mainly because of cardiovascular disease [22].

Table 2: Food Composition Before and During the End of the First Week of Hyper-

Alimentation in the Intervention Group

\begin{tabular}{|l|l|l|}
\hline Parameter & Before study & During study \\
\hline Energy from fat, carbohydrates and protein (kcal/day) & $2309(612)$ & $6516(810)$ \\
\hline Energy from fat (kcal/day) & $799(108)$ & $2657(508)$ \\
\hline Energy from fat (\%) & $35(2.9)$ & $41(7.2)$ \\
\hline Energy from carbohydrates (kcal/day) & $1120(304)$ & $3005(102)$ \\
\hline Energy from carbohydrates (\%) & $49(5.4)$ & $46(7.2)$ \\
\hline Energy from protein (kcal/day) & $390(23)$ & $854(112)$ \\
\hline Energy from protein (\%) & $17(1.8)$ & $13(2.2)$ \\
\hline Fat (g/day) & $90(12)$ & $280(33)$ \\
\hline Saturated fat (g/day) & $41(14)$ & $122(40)$ \\
\hline Monounsaturated fat (g/day) & $36(12)$ & $90(22)$ \\
\hline Polyunsaturated fat (g/day) & $14(4.2)$ & $32(11)$ \\
\hline Sugar (g/day) & $92(37)$ & $287(90)$ \\
\hline Fibre (g/day) & $25(8)$ & $40(10)$ \\
\hline
\end{tabular}

Figures are presented as means (SD). All changes compared to baseline were statistically significant except those of the energy\% from carbohydrates and the intake of fibre. Sugar equals mono- and disaccharides

From the results of this study it was observed that increase in ALT was not related to the change in waist circumference but seems to correlate with the weight increase (ratio of ALT at study end/baseline ALT to the increase in weight, $\mathrm{r}=0.52, \mathrm{p}=0.081$ ). The results also indicated that increase in caloric intake was not correlated with changes in ALT levels (either change from basal level to highest individual ALT, or to ALT change from basal levels to those at study end) or HTGC. The average intake of fat or proteins during 3 days at the end of the first or third weeks was not related to changes in ALT. On the other hand, the maximal ALT/baseline ratio correlated with carbohydrate intake during the third week $(r=0.52, p=0.05$ and corresponding figures for intake during the first week, $\mathrm{r}=0.40, \mathrm{p}=0.1$ ). The intake of sugar (mono- and disaccharides) during the third week also correlated with the maximal ALT/baseline ALT ratio (intake during the third week, $r=0.65, p=0.005$ and corresponding figures for intake at the end of the first week, $r=0.45$, $\mathrm{p}=0.06$ ).

Table 3: Number of Subjects in the Intervention Group Displaying Serum ALT Above

Reference Levels During the Study and at Follow-up

\begin{tabular}{|c|c|c|c|c|c|c|}
\hline ALT reference levels & $\begin{array}{l}\text { Baseline (men } \\
n=10 \text {, women } \\
n=6 \text { ) }\end{array}$ & $\begin{array}{l}\text { Week } 1 \text { (men } \\
\mathrm{n}=10 \text {, women } \\
\mathrm{n}=6 \text { ) }\end{array}$ & $\begin{array}{l}\text { Week } 2 \text { (men } \\
n=10 \text {, women } \\
n=6)\end{array}$ & $\begin{array}{l}\text { Week } 3 \text { (men } \\
n=10, \text { women } \\
n=6)\end{array}$ & $\begin{array}{l}\text { Week } 4 \text { (men } \\
n=10, \text { women } \\
n=6)\end{array}$ & $\begin{array}{l}\text { Persistent } \\
\text { elevation from } \\
\text { week } 1 \text { to study } \\
\text { end }\end{array}$ \\
\hline Men $>40 \mathrm{U} / 1 \dagger$ & 2 & 5 & 6 & 6 & 8 & 5 \\
\hline Men $>30 \mathrm{U} / 1 \dagger \dagger$ & 1 & 8 & 10 & 10 & 10 & 8 \\
\hline Women $>31 \mathrm{U} / 1 \dagger$ & 1 & 2 & 3 & 3 & 5 & 2 \\
\hline Women $>19 \mathrm{U} / 1 \dagger \dagger$ & 2 & 4 & 4 & 5 & 5 & 4 \\
\hline
\end{tabular}


†Upper reference limits for ALT used in NHANES III. †Updated upper reference limits for ALT.

As presented in table 1, Hepatic triglyceride content (HTGC) increased from 1.3 (2.1) \% to 3.0 (3.2)\% in the intervention group ( $p=0.003$ by the Wilcoxon signed rank test). This observed increase of HTGC did not correlate with either the increase in ALT (ratio of ALT at study end/baseline ALT to HTGC at study end/baseline, $p=0.11$, Spearman) or intake of fat, carbohydrates and protein. The increase in body weight seems to correspond with the increase in HTGC $(r=0.44, p=0.07)$ while the increase in the percentage of body fat was obviously associated to the increase in HTGC $(\mathrm{r}=0.81, \mathrm{p}<0.001)$.

It is observed from this study that the magnitude of ALT elevation only seems to correlate with those of HTGC, making it unlikely that fatty infiltration of the liver was the main cause of the rapidly increased ALT levels that were presented in many subjects. Hepatocellular damage due to other reasons than intracellular accumulation of lipids (e.g. localized inflammation) could possibly explain the elevated ALT levels [23]. As a matter of fact, if we examine the relationship of the increase in ALT to intake of different nutrients, it will be observed that fat intake was unrelated to increase in ALT while sugar and carbohydrate intake as at third week was clearly related to the ALT increase. This agrees with an earlier study by Solga et al [24] and Panchal et al. [25] who demonstrated that higher carbohydrate intake was significantly associated with an increased risk of biopsy-proven hepatic inflammation in morbidly obese patients undergoing bariatric surgery. A good number of participants displayed a spontaneous decrease of ALT levels after the initial increase, during the study, while still gaining weight by the intervention, which is surprising if inflammation was the major mediator of the ALT increase. A possible explanation for the ALT elevations in this study may be that the sudden increased supply of metabolic substrates, to the liver [26]. Monosaccharides especially will cause an enzymatic induction in hepatocytes and hence lead to the normal leakage of ALT through the cell membrane which resulted in elevated serum levels.

The observed decrease in bilirubin levels as shown by the intervention group is in line with induction of hepatic metabolic capacity rather than forthright liver cell damage.

\section{Conclusion}

From the results we can conclude that though fast foods are readily available, they should be consumed with caution because of the danger that their indiscriminate consumption can cause. Feeding fat on this fast foods leads to hyper-alimentation which pose a danger in the rise of liver marker enzymes in consumers and may affect the liver function of such people. The results of this study showed that 4 weeks of hyper-alimentation is associated with clinically significant elevations of liver marker enzymes in many subjects. It is therefore recommended that youths as well as elderly citizens should feed less on these fast foods and give attention to meeting their daily dietary need for better functioning and sound health.

\section{References}

[1]. O. A. Moronkola, Essays on issues on health (Ibadan, Royal People Ltd., 2003) 26-27.

[2]. P. O. Akinbile, Obesity and overweight in children: strategies for prevention, Journal of Nigeria Association of Sports Science and Medicine, 1(2), 2008, 1-5.

[3]. J. A. Ajala, Understanding food and nutrition (Ibadan, MayBest Publications, 2006).

[4]. E. P Konwea, and I. O. Akindutire. Perceived effects of consumption of fast Food on weight-gain among urban residents in Nigeria, Journal of International Council for Health, Physical Education, Recreation, Sports and Dance, 1 (2), 2006, $136-141$.

[5]. S.A. Bowman, S.L. Gortmaker, C.B. Ebbeling, M.A. Pereira, and D.S. Ludwig. Effects of fast food consumption on energy intake and diet quality among children in a national household survey. Pediatrics, 113 (1), 2004, 112-118.

[6]. S. Adeniyi, Soft drinks in Nigeria are dangerous to public health, Nigerian Tribune, November 10: $23,2004$.

[7]. P. J. Wart, What is junk food? Health Plus. September, 3. Retrieved December 29, 2014 from http://vanderbiltowc. wellsource.com/dh/content.asp?ID = 260, 2006.

[8]. S.B. Racette, S.S. Deusinger, and R.H. Deusinger: Obesity: overview of prevalence, etiology, and treatment, Phys Ther. 83 (3),2003, 276-288.

[9]. R. Rosenheck, Fast food consumption and increased caloric intake: a systematic review of a trajectory towards weight gain and obesity risk. Obes Rev. 9 (6), 2008, 535-47.

[10]. G. Wanten, P.C. Calder and A. Forbes Managing adult patients who need home parenteral nutrition, BMJ, 342,2011,d1447.

[11]. D.L. Kaminski, The effect of hyperalimentation on hepatic lipid content and lipogenic enzyme activity in rats and man, Surgery, 88(1), 1980, 93-100

[12]. V. Lecoultre, L. Egli, G. Carrel, F. Theytaz, R. Kreis, P. Schneiter, A. Boss, K. Zwygart, K.A. Lê, M. Bortolotti, C. Boesch, and L. Tappy, Effects of fructose and glucose overfeeding on hepatic insulin sensitivity and intrahepatic lipids in healthy humans, Obesity (Silver Spring) 21(4), 2013, 782-785.

[13]. S. Reitman and S. Frankel, A colorimetric method for the determination of serum glutamate oxaloacetate transaminases, Am J Clin Pathol., 28, 1957, 56-63.

[14]. Centers for Disease Control and Prevention. National Health and Nutrition Examination Survey: Standard Biochemistry Profile, 2008.

[15]. W. Heins, et al., Test for the quantitative determination of the total activity of alkaline phosphatase (EC 3.1.3.1) in blood serum or plasma using Reflotron. Eur J ClinChem Biochem, 33, 1995, 231. 
[16]. E. Ravussin, S. Lillioja, T.E. Anderson, L. Christin, C. Bogardus, Determinants of 24-hour energy expenditure in man: Methods and results using a respiratory chamber. J Clin Invest., 78, 1986, 1568-1578.

[17]. F. Rosquivist, Iggman D, Kullberg J, Cedernaes J, Johansson H.E, Larsson A Johansson L, Ahlström H, Arner P, Dahlman I, and U. Risérus, Overfeeding polyunsaturated and saturated fat causes distinct effects on liver and visceral fat accumulation in humans, Diabetes, 63(7), 2014, 2356-68.

[18]. V . Lecoultre, L. Egli, Carrel G, Theytaz F, Kreis R, Schneiter P, Boss A, Zwygart K, Lê KA, Bortolotti M, C. Boesch, and L. Tappy, Effects of fructose and glucose overfeeding on hepatic insulin sensitivity and intrahepatic lipids in healthy humans, Obesity (Silver Spring). 21(4), 2013, 782-5.

[19]. G.C. Farrell and C.Z., Larter: Non-alcoholic fatty liver disease: from steatosis to cirrhosis, Hepatology, 43 (2 Suppl 1), 2006, S99S112.

[20]. K.J. Nadeau, G. Klingensmith and P. Zeitler, Type 2 diabetes in children is frequently associated with elevated alanine aminotransferase, J Pediatr Gastroenterol Nutr. 41 (1), 2005, 94-98.

[21]. J.B. Schwimmer, Definitive diagnosis and assessment of risk for nonalcoholic fatty liver disease in children and adolescents. Semin Liver Dis. 27 (3), 2007, 312-318.

[22]. D.H. Leung, K. Williams, J.K. Fraley, and W.J. Klish, Age- and ethnic-specific elevation of ALT among obese children at risk for nonalcoholic steatohepatitis (NASH): implications for screening, Clin Pediatr (Phila), 48 (1), 2009, 50-57.

[23]. A. Fraser, M.P. Longnecker, and D.A. Lawlor: Prevalence of elevated alanine aminotransferase among US adolescents and associated factors: NHANES 1999-2004, Gastroenterology. 133 (6), 2007, 1814-1820.

[24]. S. Solga, A.R. Alkhuraishe, J.M. Clark, et al., Dietary composition and nonalcoholic fatty liver disease, Dig. Dis.Sci. 49, 2004,1578-1583.

[25]. S.K. Panchal, H. Poudyal, A. Iyer, Nazer R, Alam A, Diwan V, K. Kauter: High-carbohydrate, High-fat Diet - induced Metabolic Syndrome and Cardiovascular Remodeling in Rats. J Cardiovasc Pharmacol., 57, 2011, 611-624.

[26]. A.J. Hanley, L.E. Wagenknecht, Festa A, R.B. D'Agostino, S.M. Haffner, Alanine aminotransferase and directly measured insulin sensitivity in a multiethnic cohort: the Insulin Resistance Atherosclerosis Study, Diabetes Care, 30, 2007, $1819-1827$. 